\title{
Nas páginas de Capitães da areia: táticas e astúcias contra a ordem estabelecida
}

\author{
On the pages of Capitães da areia: \\ tactics and cunning acts against the established order
}

\author{
MÁRCIA Rios DA SILVA \\ JADSON SANTANA DA LUZ \\ Universidade do Estado da Bahia
}

\begin{abstract}
Resumo: Neste artigo, realiza-se uma análise interpretativa da narrativa Capitães da areia, de Jorge Amado, no confronto com o contexto sociojurídico dos anos 1930. A partir da leitura do romance, o estudo visa discutir as táticas utilizadas pelos personagens para fazer frente às estratégias de controle colocadas em jogo pelo Estado brasileiro, que visava conter, em nome da ordem e da paz social, uma miríade de crianças em situação de abandono, menores vulneráveis que tinham as ruas da capital baiana como o seu único espaço de sobrevivência. Capitães da areia expõe esse cenário e se coloca do lado dos desfavorecidos sociais ao narrar as astúcias e táticas empreendidas contra a opressão social que os cerca. Os estudos de Michel de Certeau serviram para interpretar o desenrolar dessa luta.
\end{abstract}

Palavras-chave: Capitães da areia; leis; contexto sociojurídico; táticas; astúcia; estratégias.

\begin{abstract}
The aim of this article is to provide an interpretative analysis of the novel Capitães da areia by Jorge Amado while confronting the social and legal context in the 1930s. Having the text as its starting point, the study discusses the tactics used by the characters in the novel in order to face the control strategies put into play by the Brazilian state which, in the name of social peace and order, aimed at keeping a myriad of abandoned and vulnerable children under control. These kids had the streets of Salvador as their only space for survival. Capitães da areia exposes this scenario and places itself on the side of the social disadvantaged by narrating their cunning acts and tactics against the social oppression surrounding them. The studies carried out by Michel de Certeau were used to interpret the development of this fight.
\end{abstract}

Keywords: Capitães da areia; law; social and legal context; tactics; cunning acts.

Livro marcado pelo estigma da incineração, perseguido pela censura do Estado Novo, Capitães da areia, publicado por Jorge Amado em 1937, narra situações cotidianas protagonizadas por um grupo de crianças e adolescentes nas ruas da cidade de Salvador. O romance expõe os maus tratos duma sociedade opressora a um grupo de crianças vítimas do abandono, vulneráveis, portanto, às mazelas sociais, e que encontram as ruas da capital baiana como o seu único espaço de sobrevivência.

Chamados de capitães da areia, e sobrevivendo de pequenos furtos e assaltos, muitos desses menores, tal como apresenta a narrativa, foram abandonados pelos pais ou, por circunstâncias diversas, tornaram-se órfãos. Essas crianças têm como esconderijo um trapiche desativado na beira do cais, onde buscam guarida nas fugas da polícia e também onde guardam e dividem o que conseguem com os furtos. Desprezados pelo Estado, sem família, encontrando apenas a piedade de um pároco sensível à situação, os menores se organizam estabelecendo regras de convivência e laços de solidariedade. Na travessia de um cotidiano adverso, os capitães da areia, liderados por Pedro Bala, enfrentam a terrível epidemia de varíola, arquitetam invasões à delegacia de polícia, tramam assaltos às mansões do rico bairro da Graça, vão às festas do candomblé da mãe Aninha, troçam do modo de vida que leva a elite e criam táticas para baldar a opressão social sofrida.

Boa parte da obra de Jorge Amado, sem dúvida, pode ser caracterizada pelas articulações que o escritor estabelece entre cidade, cultura, política e identidade. As cidades, seja Salvador, sejam as demais tematizadas pelo escritor, são representadas como locus onde se imbricam 
repressão política e cultura popular, cor de pele e luta de classes, liberdade e abandono, solidariedade e indiferença. Isto é, no universo romanesco amadiano a cidade se faz perceptível como espaço culturalmente heterogêneo, no qual o binômio exclusão social e luta por sobrevivência está presente como linha mestra.

O romance Capitães da areia, dividido em três partes e mais um prólogo, não narra apenas o drama de crianças órfãs, mas também uma complexa rede de sociabilidades tecidas no cotidiano de uma cidade, cujos verdadeiros "donos" é a imensa população de pobres que faz das ruas o palco de uma luta renhida pela liberdade. É um livro sobre uma saga coletiva, na qual as ruas de Salvador e seus personagens vêm ganhar protagonismo.

No romance, percebe-se muito bem que a narrativa sobre a cidade está atrelada ao modo pelo qual o texto expõe as vivências e a dinâmica cultural da população pobre nas vielas sinuosas da velha urbe. Embora apresente um espaço urbano hostil e segregante, o livro revela a relação simbiótica entre a cidade e seus personagens. A cidade de Salvador, em Capitães da areia, não é apresentada como simples pano de fundo. Ela é a própria condição de possibilidade da narrativa, pois é o lugar onde se articulam cultura, política, pobreza, repressão e luta pela sobrevivência. É nesse sentido que o grupo dos capitães da areia está ligado umbilicalmente ao fluxo urbano caracterizador da cidade. "Vestidos de farrapos, sujos, semiesfomeados, agressivos, soltando palavrões e fumando pontas de cigarro, eram, em verdade, os donos da cidade, os que a conheciam totalmente, os que totalmente a amavam, os seus poetas" (AMADO, 2009, p. 27).

Capitães da areia é uma síntese da realidade social brasileira de 1930. Nele, vemos expresso o resultado de séculos de abandono e desprezo que os espoliados pelo poder econômico receberam das elites e dos poderes estatais constituídos. O amargor de uma vida precarizada e perseguida é o que se pode ver nas páginas do livro considerado subversivo pelo Estado Novo de Getúlio Vargas. Portanto, é um romance que expõe um imenso problema social, isto é, um drama causado pela exclusão e pelo esquecimento.

A elite brasileira esteve atenta aos potenciais perigos que poderiam advir do seio das classes populares. Portanto, desde meados do século XIX, buscou pensar meios de contenção e dispositivos de segurança para captura de indivíduos e grupos populacionais que não se enquadrassem às regras ditadas pelos quadros sociais estabelecidos. Com o passar do tempo, o que se viu foi a sofisticação dos braços de operacionalização do sistema penal, sobretudo durante o longo período em que Getúlio Vargas esteve no poder. A essas configurações tramadas, escalonadas e calculadas pelo poder, Michel de Certeau chamou de "estratégia", que é, nas palavras do autor, o cálculo (ou manipulação) das relações de forças que se torna possível a partir do momento em que um sujeito de querer e poder (uma empresa, um exército, uma cidade, uma instituição científica) pode ser isolado. A estratégia postula um lugar suscetível de ser circunscrito como algo próprio e ser a base de onde se podem gerir as relações com uma exterioridade de alvos ou ameaças (os clientes ou os concorrentes, os inimigos, o campo em torno da cidade, os objetivos e objetos da pesquisa etc.). Como na administração de empresas, toda racionalização "estratégica" procura em primeiro lugar distinguir de um "ambiente" um "próprio", isto é, o lugar do poder e do querer próprios. Gesto cartesiano, quem sabe: circunscrever um próprio num mundo enfeitiçado pelos poderes invisíveis do Outro. Gesto da modernidade científica, política ou militar (1998, p. 99) [aspas do autor].

$\mathrm{Na}$ narrativa de Capitães da areia estratégias de repressão ganham referência. Mas são referenciadas de um modo distinto daquele que costuma trazer o discurso institucional, que as trata como eficientes meios de reforma moral e reinserção social. Nesse romance, as estratégias repressivas do sistema de poder são mostradas quase sempre com suas falhas, suas fissuras, com seus embaraços e em sua ineficiência. É nas brechas deixadas por esses deslizes, por essas pequenas distrações do poder, que os "capitães da areia" encontram espaço para gestar aquilo que Certeau chamou de "táticas".

Um cálculo que não pode contar com um próprio, nem portanto com uma fronteira que distingue o outro como totalidade visível. A tática só tem por lugar o do outro. Ela aí se insinua, fragmentariamente, sem apreendê-lo por inteiro, sem poder retê-lo à distância. Ela não dispõe de base onde capitalizar seus proveitos, preparar suas expansões e assegurar uma independência em face das circunstâncias. [...] Ao contrário, pelo fato de seu não lugar, a tática depende do tempo, vigiando para 'captar no voo' possibilidades de ganho. O que ela ganha, não guarda. Tem constantemente que jogar com os acontecimentos para os transformar em 'ocasiões'. Sem cessar, o fraco deve tirar partido de forças que lhe são estranhas. Ele o consegue em momentos oportunos onde combina elementos heterogêneos [...], mas a sua síntese intelectual tem por forma não um discurso, mas a própria decisão, ato e maneira de aproveitar a 'ocasião' (CERTEAU, 1998, p. 46-47 [aspas do autor]).

Jogar com os acontecimentos, tirar proveito das distrações de guardas e transeuntes, disfarçar-se de mendigo, instalar esconderijo em zonas abandonadas, valer-se do silêncio nas ruas dos bairros estabelecidos, irromper contra os palacetes e encenar situações para

\footnotetext{
Neste artigo, em diferentes momentos, os personagens do romance são referidos como "capitães da areia", numa assumida adesão à perspectiva do narrador.
} 
garantir "níqueis" ou oportunidade de furto, são modos táticos de baldar a ordem que proliferam em Capitães da areia. Assim leciona Certeau:

Essas performances operacionais dependem de saberes muito antigos. Os gregos as designavam de métis. Mas elas remontam a tempos muito mais recuados, a imemoriais inteligências com as astúcias e simulações de plantas e de peixes. Do fundo dos oceanos até as ruas das megalópoles, as táticas apresentam continuidades e permanências. Em nossas sociedades, elas se multiplicam com o esfarelamento das estabilidades locais como se, não estando mais fixadas por uma comunidade circunscrita, saíssem de órbita e se tornassem errantes (1998, p. 47).

Na luta contra as instituições colocadas na arena pelo Código de Menores de 1927, contra as regras de uma suposta boa moralidade, contra as árduas reprimendas das práticas penais de tortura e contra as máquinas de guerra instituídas pelo Governo Vargas, só restavam aos capitães da areia as transgressões possibilitadas pelas táticas, já que, no fim das contas, eles sabiam demais as leis do reformatório, as escritas e as que cumpriam. Portanto, os personagens que compõem o romance não são insensíveis aos preconceitos de classe nem às armadilhas montadas contra eles no tecido social. Em Bahia de todos os santos: guia de ruas e mistérios de Salvador, escrito em 1944, numa referência explícita a Capitães da areia Jorge Amado revela alguns modos de contra-atacar desses personagens e também mostra, numa interlocução com seus leitores, que eles representam sujeitos reais, conhecidos de longa data.

Os molecotes atrevidos, o olhar vivo, o gesto rápido, a gíria de malandro, os rostos chapados de fome, vos pedirão esmola. Praticam também pequenos furtos. Há quarenta anos escrevi um romance sobre eles. Os que conheci naquela época são hoje homens maduros, malandros do cais, com cachaça e violão,operários de fábrica, ladrões fichados na polícia, mas os Capitães da Areia continuam a existir, enchendo as ruas, dormindo ao léu. Não são um bando surgido do acaso, coisa passageira na vida da cidade. É um fenômeno permanente, nascido da fome que se abate sobre as classes pobres. [...] Parecem pequenos ratos agressivos, sem medo de coisa alguma, de choro fácil e falso, de inteligência ativíssima, soltos de língua, conhecendo todas as misérias do mundo numa época em que as crianças ricas ainda criam cachos e pensam que os filhos vêm de paris no bico de uma cegonha (AMADO, 2012, p. 344).

Malandragem, vivacidade, rapidez, atrevimento, o que são, senão potenciais de força, táticas, contrapoderes, modos de insurreição aptos a suscitar o combate contra a coação da ordem estabelecida? É mobilizando essas forças, que provêm das margens, que os capitães da areia vão conflagrar alvoroços, promover revoltas e instaurar os movimentos de subversão típicos das táticas.

A prática de delitos é uma das táticas privilegiadas pelo narrador de Capitães da areia no decorrer da história. Trata-se de uma arma de luta, de uma forma de combater e demarcar uma linha de fronteira entre os princípios morais supostamente civilizados das elites e o modo de vida que levava o grupo dos capitães da areia. Nesse sentido, o delito no romance é colocado como operador de sentido por meio do qual se estabelece uma constelação de relações sociais. Conforme Josefina Ludmer, "desde o começo mesmo da literatura, o delito aparece como um dos instrumentos mais utilizados para definir e fundar uma cultura: para separá-la da não-cultura e para marcar o que a cultura exclui" (LUDMER, 2002, p. 10).

Ao trazer o delito como instrumento crítico, Jorge Amado articula e apresenta formas de organização social, construindo a identidade cultural dos capitães da areia. Nessa esteira, o escritor se serve do delito como meio de fazer crítica cultural, social, política, literária e, por que não, econômica, visto que nos apresenta vidas de sujeitos que lutam e sobrevivem, a despeito da pobreza que pesa sobre eles.

Em Capitães da areia, o Corredor da Vitória, bairro das elites, é apresentado como cenário de uma das investidas do grupo dos capitães. Trata-se do assalto à casa do Comendador José Ferreira, apresentado na narrativa como um dos mais abastados e creditados negociantes da cidade. No prólogo que compõe o romance, o fictício Jornal da Tarde relata a cena desse episódio nos seguintes termos:

\section{ASSALTO}

Não tinham passado ainda cinco minutos quando o jardineiro Ramiro ouviu gritos assustados vindos do interior da residência. Eram gritos de pessoas terrivelmente assustadas. Armando-se de uma foice o jardineiro penetrou na casa e mal teve tempo de ver vários moleques que, como um bando de demônios (na expressão curiosa de Ramiro), fugiam saltando as janelas, carregados com objetos de valor da sala de jantar. A empregada que havia gritado estava cuidando da senhora do comendador, que tivera um ligeiro desmaio em virtude do susto que passara. O Jardineiro dirigiu-se às pressas para o jardim, onde teve lugar a

\section{LUTA}

Aconteceu que no jardim a linda criança que é Raul Ferreira, de 11 anos, neto do comendador, que se achava de visita aos avós, conversava com o chefe dos "Capitães da Areia", que é reconhecível devido a um talho que tem no rosto. Na sua inocência, Raul ria para o malvado, que sem dúvida pensava em 
furtá-lo. O jardineiro se atirou então em cima do ladrão. Não esperava, porém, pela reação do moleque, que se revelou um mestre nestas brigas. E o resultado é que, quando pensava ter seguro o chefe da malta, o jardineiro recebeu uma punhalada no ombro e logo em seguida outra no braço, sendo obrigado a largar o criminoso, que fugiu (AMADO, 2009, p. 10-11).

A extensa citação serve para perceber como as táticas narradas por Jorge Amado são apresentadas no confronto entre a imponência do suposto clima de segurança do rico casarão e a pobreza articulada com a destreza dos capitães da areia. Nessa cena do romance, o saber prático adquirido nos treinos de capoeira com o amigo Querido-de-Deus valeu a Pedro Bala a esquiva, o certeiro contragolpe e, por fim, a fuga. Como se vê, a capoeira, uma prática considerada tipo penal até 1937, é uma das astúcias valorizadas pela narrativa. Talvez uma forma encontrada pelo autor para, de um lado, denunciar o absurdo da proibição e, de outro, expressar seu apreço aos amigos capoeiras.

Vale dizer que os empreendimentos das táticas só podem ser pensados em Capitães da areia se remetidos ao tecido cultural pelo qual se enredam os personagens. $\mathrm{Na}$ narrativa seus protagonistas são como que um amálgama de cruzamentos culturais, uma espécie de herdeiros de saberes seculares, da esperteza aprendida no cotidiano. São desses saberes práticos, saberes imemoriais como quis Certeau, que sucedem as táticas. Assim, é ao lado dos que forjam as táticas que a narrativa se inclina para mostrar as vielas, as quermesses, os candomblés, toda uma cultura popular que à época se encontrava escamoteada, obscurecida e perseguida na cidade de Salvador. A evidência dessa colocação pode ser observada através do ocorrido no episódio intitulado "Aventura de Ogum", em que é creditado aos capitães, pela ialorixá Don'Aninha, o resgate da imagem de Ogum, que havia sido levada numa batida policial. Conforme o narrador,

Don'Aninha disse aos meninos com uma voz amarga Não deixam os pobres viver... Não deixam nem o deus dos pobres em paz. Pobre não pode dançar, não pode cantar para seu deus, não pode pedir uma graça a seu deus - sua voz era amarga, uma voz que não parecia da mãe-de-santo Don'Aninha. - Não se contentam de matar os pobres a fome... Agora tiram os santos dos pobres... - e alçava os punhos. [...] Quando a deixaram, rodeada das suas filhas-de-santo, que beijavam sua mão, Pedro Bala prometeu - Deixa estar, mãe Aninha, que amanhã te trago Ogum (AMADO, 2009, p. 94).

Pouco tempo depois, os capitães da areia arquitetam um estratagema. A ideia era que um deles se infiltrasse na Central de Polícia, onde o Ogum de Don'Aninha estava apreendido. Pedro Bala toma a frente do intento e, ao forjar um assalto no bairro do Campo Grande, deixa-se capturar. Já na Central de Polícia, "o chefe dos capitães" localiza a imagem de Ogum, envolve-a no seu paletó e aguarda que o chamem para a oitiva. Na oitiva, Pedro Bala inventa para o comissário que é da ilha de Itaparica, Mar Grande, e que o pai não pode voltar para buscá-lo por conta do temporal. Como não podia ficar na rua, empreendeu o assalto para que o guarda o levasse à delegacia.

Tomando como impossível que uma criança daquela idade estivesse inventando uma história tão cheia de detalhes como a apresentada, o comissário manda que se ponha o menor em liberdade. É quando Pedro Bala pede para buscar o paletó que havia esquecido. Em seguida, coloca-o "debaixo do braço, nem parecia trazer a imagem envolvida nele. Atravessaram o corredor novamente, o guarda o deixou na porta. Pedro tomou para o Largo dos Aflitos, rodeou o velho quartel, desabou pela Gamboa de Cima" (AMADO, 2009, p. 105).

Não só o grupo de menores abandonados se utiliza das táticas, como também aqueles que se solidarizam com a sua situação. O padre José Pedro faz uso de sua autoridade de pequeno pároco para convencer as beatas a adotarem um daqueles meninos. Por isso, escreve uma carta ao Jornal da Tarde em solidariedade aos capitães da areia, o que o leva a ser denunciado ao alto clero, a sofrer reprimenda do Cônego, que o acusa de favorecer práticas comunistas e de atentar contra as leis da Igreja e do Estado. Mas, por fim, consegue permanecer como padre e não quebra o vínculo de amizade com os capitães da areia. Por sua vez, a costureira Ricardina também se coloca contra as agruras pelas quais passam as crianças no Reformatório. Para isso, escreve carta ao jornal, desculpa-se do mau uso da língua oficial, meio de se fazer ouvir, denuncia os desmandos do diretor da instituição e desafia o veículo de imprensa a mandar um representante "para ver como são tratados os filhos dos pobres que têm a desgraça de cair nas mãos daqueles guardas sem alma" (AMADO, 2009 , p. 16). Se entendemos, com Foucault, que todo exercício de poder pressupõe um contrapoder, vemos que há aí uma espécie de micropolítica do cotidiano.

Em relação à justiça, a luta pode tomar várias formas. Em primeiro lugar, pode-se usar contra ela suas próprias armas, por exemplo, apresentar queixa contra a polícia. Isso não é evidentemente um ato de justiça popular; é a justiça burguesa apanhada em uma armadilha. Em segundo lugar, pode-se fazer guerrilhas contra o poder de justiça e impedi-lo de se exercer. Por exemplo, escapar da polícia, ridicularizar o tribunal, ir pedir satisfações a um juiz. Tudo isso é guerrilha antijudiciária [...] (FOUCAULT, 1998, p. 66).

E Capitães da areia esboça uma espécie de guerrilha antijudiciária. $\mathrm{O}$ atabalhoamento do Juiz de Menores, os 
vícios e as faltas do Chefe de Polícia, a displicência do Bedel e do Comissário são modos de ridicularização, denúncia e exposição de um sistema judiciário que anda em descompasso com as regras de eficiência que estabelecem os códigos. Localiza-se em Capitães de areia, mesmo que precariamente, a figuração de um saber jurídico que se produz no âmbito das praticas cotidianas. Uma espécie de direito dos marginalizados. Prolifera na narrativa um sem número de regras de cordialidade, normas de respeitabilidade, táticas de sobrevivência que têm como foco a união dos "fracos" contra a investida da opressão social.

Contra as leis do Estado repressor, as leis dos capitães da areia. Essa é a batalha que se observa nas páginas do romance. É em defesa da regra principal do grupo, a de não furtarem uns aos outros, que o personagem Pedro Bala se vê obrigado a expulsar um dos meninos. Também em nome das leis dos capitães da areia, o personagem Sem Pernas desconsidera a possibilidade de ficar vivendo numa luxuosa casa da Graça onde o acolheram como "pobre órfão". Na verdade, uma tática para se infiltrar na casa e arquitetar um grande roubo. Acerca da lei do grupo, pensava Sem Pernas que "antes de tudo estava a lei do grupo, a lei dos Capitães da Areia. Os que a traíam eram expulsos e nada de bom os esperava no mundo" (AMADO, 2009, p. 126). Por fim, o personagem Pirulito aborta uma tentativa de furto, "porque ele pensava que trair as leis (nunca tinham sido escritas, mas existiam na consciência de cada um deles) dos Capitães da Areia era um pecado também" (AMADO, 2009, p. 111). Durante toda a história contada no romance, o narrador refere-se a esse código de ética do grupo de meninos abandonados.

Assim, "as leis dos capitães da areia" expressavam um senso ético de trato humanitário. Ao relatar uma caminhada do grupo em direção ao encontro do grupo rival, chefiado por Ezequiel, menor que havia sido expulso do trapiche, o narrador ressalta que "vão alegres. Levam navalhas e punhais nas calças. Mas só o sacarão se os outros puxarem. Porque os meninos abandonados também têm uma lei e uma moral, um sentido de dignidade humana" (AMADO, 2009, p. 189).

Pelo que é possível depreender do texto de Certeau (1998), as táticas também são meios que os despossuídos encontram para lutar contra as estratégias de acumulação. $\mathrm{Se}$, de um lado os muros, os esconderijos e os sistemas de vigilância estão postos para resguardar nas chácaras e nos palacetes grande volume de peças de ouro, do outro, os capitães da areia diagramam ciladas, ardis e truques para malograr o somítico hábito de acumular das elites. Robinhoodianos por necessidade, os heróis do romance ironizam com os agentes acauteladores do capital da burguesia. No diálogo, em que planejavam furtar chapéus de feltro no bairro da Vitória, um dos capitães da areia responde: "Tu liga pra guarda? Se ainda fosse tira... Guarda é pra correr picula" (AMADO, 2009, p. 33).

$\mathrm{O}$ personagem Gato não poderia ficar fora do catálogo de astúcias que Jorge Amado explora no romance. Talvez o seu codinome seja uma referência sarcástica ao uso comum do termo "gatuno", expressão pejorativa endereçada aos meninos de rua pelos jornais, nas primeiras décadas do século passado. O certo é que, no romance, Gato é perito em armar "treitas". Ágil no jogo com o seu baralho viciado, o moleque arrancava altas somas do desavisado que se enganasse com a sua aparência infantil.

A primeira cilada armada por Gato foi na casa do Sr. Gastão, flautista e namorado da prostituta Dalva, mulher pela qual o menor se apaixonara. Atendendo ao pedido feito por Dalva, ir até à casa do músico avisar que ela o esperava, o menino flagra Gastão bêbado na cama com uma amante. Tanto o flautista quanto a mulher escarnecem do pequeno garoto. A mulher perguntava: "quem é esse cocadinha?". O músico respondia: "É um filhote somente. Não faz medo". Por fim, convidaram o menor para entrar. Nesse meio tempo, Gato já aproveitava o descuido do casal embriagado e furtava a bolsa da amante que estava esquecida na cadeira sobre os vestidos. "Na rua o Gato contou sessenta e oito mil-réis. Jogou a bolsa no pé da escada, meteu o dinheiro no bolso. E foi para rua de Dalva, assoviando" (AMADO, 2009, p. 42). A principal astúcia que se observa nas ações desse personagem é o proveito que ele tirava da imagem de criança.

Nas páginas de Capitães da areia há toda uma narrativa que se volta à exposição de uma religiosidade sincrética. Xangô, Omolu, Ogum, Santo Antônio, Santa Virgem da Conceição e Nossa Senhora das Sete Dores estão relacionados no romance como uma rede complexa de elementos heterogêneos. Se "João Grande acreditava era em Xangô, em Omolu, nos deuses dos negros que vieram da África. O Querido-de-Deus [...] misturava-os com os santos dos brancos que tinham vindo da Europa". (AMADO, 2009, p. 107).

Também Pirulito, menino que furtava santos, amalgamava uma inventiva hagiografia de Santo Antônio. Para ele, o santo franciscano era um mártir brasileiro, um revoltoso justiceiro, que havia sido condenado à forca depois de tentar salvar o pai do cadafalso. Nas palavras do narrador: "Pirulito contava a história de Santo Antônio [...] do modo como Professor lia histórias heróicas de marinheiros corajosos e revoltosos" (AMADO, 2009, p. 180). Percebe-se que, como Menocchio de $O$ queijo e os vermes, de Ginzburg, Pirulito reelabora, adultera e se apropria da imagem do santo português para colocá-la ao lado dos capitães da areia. Assim, o santo reinventado torna-se mais um guia, uma entidade protetora dos menores abandonados. 
Certeau esteve atento a esse tipo de astúcia urdida no seio das classes populares quando analisou práticas religiosas de comunidades rurais.

Os "crentes" rurais desfazem assim a fatalidade da ordem estabelecida. E o fazem utilizando um quadro de referência que, também ele, vem de um poder externo (a religião imposta pelos missionários). Reempregam um sistema que, muito longe de lhes ser próprio, foi construído e propagado por outros, e marcam esse reemprego por "super-ações", excrescência do miraculoso que as autoridades civis e religiosas sempre olham com suspeita, e com razão, de contestar às hierarquias do poder e do saber da sua razão. Um uso ("popular") da religião modifica-lhe o funcionamento (CERTEAU, 1998, p. 78) [aspas do autor].

Mas não é só em Capitães da areia que o sincretismo religioso está presente. A fusão entre "santos negros" e "santos brancos" é uma característica da escrita amadiana. É algo que se pode ver em outros romances do escritor, vestígio da sua cosmovisão. Ao tratar da procissão de Nosso Senhor Bom Jesus dos Navegantes, Jorge Amado revela o prisma sincrético pelo qual vê a cultura e a religiosidade baiana.

Na cidade do Salvador da Bahia de Todos-os-Santos, as cores, as coisas, os sentimentos, os ritos, os deuses são misturados, nossa verdade é a mistura de raças, de culturas, de crenças, de ritmos, de alegrias e dores, de lutas de escravos malês, jejes, nagôs, congos e angolas, para criar a nação brasileira, original e única, civilização e cultura mestiças, a luminosa face de nosso povo. Na galeota do Senhor dos Navegantes viaja também Iemanjá (AMADO, 2012, p. 122).

Arte do furto, jogo de imitação, lance de truques, são os procedimentos que utilizam os saltimbancos da narrativa de Capitães da areia. É do uso de um desses ardis que advém o apelido do Professor. Esse personagem, cujo nome de batismo era João José, passará a ser chamado de Professor a partir do momento em que "num livro furtado ele aprendera a fazer mágicas com lenços e níqueis e também porque, contando aquelas histórias que lia e muitas que inventava, fazia a grande e misteriosa mágica de os transportar para mundos diversos" (AMADO, 2009, p. 30). Além de ilusionista e um dos principais mentores dos planos de roubo, era um hábil ladrão de livros. "Desde o dia em que furtara um livro de histórias numa estante de uma casa da Barra, se tornara perito nestes furtos" (AMADO, 2009, p. 30).

Digno da alcunha, o Professor ainda se fazia um arguto contador de história. Muitos do grupo levavam jornais até o trapiche, para que ele procedesse à leitura, já que era o único que lia correntemente. No romance, assim é apresentado esse "pequeno" narrador:
Gostava de saber coisas e era ele quem, muitas noites, contava aos outros histórias de aventureiros, de homens do mar, de personagens heroicos e lendários, histórias que faziam aqueles olhos vivos se espicharem para o mar ou para as misteriosas ladeiras da cidade, numa ânsia de aventuras e de heroísmo. [...] o treino diário da leitura despertara completamente sua imaginação e talvez fosse ele o único que tivesse uma certa consciência do heroico das suas vidas. Aquele saber, aquela vocação para contar histórias, fizera-o respeitado entre os Capitães da Areia, se bem fosse franzino, magro e triste, o cabelo moreno caindo sobre os olhos apertados de míope (AMADO, 2009, p. 30).

Ao que parece, esses singulares modos de leitura, que redirecionam e cruzam cultura popular e cultura letrada, são práticas que datam de muito tempo, engenhos interpretativos urdidos no decorrer dos séculos. O já citado livro de Ginzburg revela isso ao apresentar como, no século XVI, o moleiro Menocchio lia textos "destinados a grupos intelectuais dos mais refinados" (2006, p. 19). O historiador revela a existência de uma "circularidade cultural", isto é, "[...] influxo recíproco entre cultura subalterna e cultura hegemônica, particularmente intenso na primeira metade do século XVI" (2006, p. 15).

Certeau tratou das atividades de leitura cotidianamente realizadas pelos consumidores, em centros urbanos americanos e europeus, entre os anos de 1974 a 1978. Para o teórico, os leitores não estão entregues à passividade diante das formalizações impostas pelos "aparelhos escriturísticos da disciplina". Ao contrário, "no espaço tecnocraticamente construído, escrito e funcionalizado onde circulam, as suas trajetórias formam frases imprevisíveis, 'trilhas' em parte elegíveis" (CERTEAU, 1998, p. 45).

Em Capitães da areia, é da leitura de narrativas de jornais, reelaboradas pelo Professor, que o personagem Volta Seca enxergava no bando de Lampião os revolucionários donos da caatinga, os transgressores que lutavam contra a opressão dos coronéis do sertão. Ávido para saber da notícia que trazia o jornal Diário, o menor entra no Trapiche à procura do Professor para que este leia o fragmento sobre Lampião.

- Quero que tu leia pra eu ouvir essa notícia de Lampião que o Diário traz.Tem um retrato.

- Deixa pra amanhã que eu leio.

- Lê hoje, que eu amanhã te ensino a imitar direitinho um canário.

O Professor buscou uma vela, acendeu, começou a ler a notícia do jornal. Lampião tinha entrado numa vila da Bahia, matara oito soldados, deflorara moças, saquearaos cofres da Prefeitura. O rosto sombrio de Volta Seca se iluminou. Sua boca apertada se abriu num sorriso. E ainda feliz deixou o Professor, que apagava a vela,e foi para o seu canto. Levava o jornal para cortar o retrato do grupo de Lampião. Dentro dele ia uma alegria de primavera (AMADO, 2009, p. 46-47). 
Volta Seca é um dos capitães que mais odiava a polícia. Toda vez que sabia do assassinato de algum soldado pelo bando de Lampião era tomado por uma imensa felicidade. $\mathrm{O}$ grande ódio decorre da tarde em que soldados o pegaram. Na ocasião, tinha 16 anos. Os agentes o torturaram e ele xingava a todos, inclusive o delegado. "Ele não soltou um grito enquanto apanhou. Oito dias depois o puseram na rua, e ele saiu quase alegre, porque agora tinha uma missão na vida: matar soldados de polícia" (AMADO, 2009, p. 237). O ódio do personagem estava impresso no seu rosto sombrio, nas marcas que o sistema penal deixara no seu corpo.

Mas não era só ódio que Volta Seca possuía, tinha também um grande talento em imitar animais, os mais vários, sobretudo os do sertão. Tal astúcia foi o que rendeu ao Nhozinho França, proprietário do velho carrossel instalado no bairro de Itapagipe, o lucro decorrente do largo acesso das crianças atraídas pelo chamariz das imitações do personagem.

Em frente à bilheteria Volta Seca imita vozes de animais e chama o público. Leva uma cartucheira como se estivesse no sertão. Nhozinho França achou que isto chamaria a atenção do povo e Volta Seca parece mesmo um cangaceiro com o chapéu de couro e a cartucheira atravessada. E imita animais até que se reúnam homens, mulheres e crianças na sua frente. Então oferece entradas, que as crianças compram. Vai uma alegria por toda a praça (AMADO, 2009, p. 66-67).

Imitações, pantomimas, dribles, acrobacias são lances, táticas de combate usadas contra as estratégias do poder estabelecido. No capítulo "Como um trapezista de circo", o Sem-Pernas, mesmo manco, jogava picula com os guardas. "Sem-Pernas corria de um lado para outro da rua, os guardas avançavam. Ele fez que ia escapulir por outro lado, driblou um dos guardas, saiu pela ladeira" (AMADO, 2009, p. 242).

Não era apenas a rapidez na elaboração das táticas de escape que tornava difícil a apreensão dos capitães da areia. Entre o grupo também estava assentada uma espécie de lei antidelação, um preceito de lealdade estabelecendo que, se porventura fossem presos, não deveriam revelar a identidade dos demais e menos ainda o esconderijo no trapiche. É em respeito a esta cláusula ética que Pedro Bala se mantém silencioso na delegacia, mesmo estando submetido a tormentosa tortura. O protagonista também se negou a dar informações do grupo ao fictício Jornal da Tarde, conforme o articulista.

Na Chefia de Polícia quisemos ouvir Pedro Bala. Mas ele nada nos disse, como tampouco quis declarar às autoridades o lugar onde dormiam e guardavam seus furtos os “Capitães da Areia”. Só declarou seu nome, disse que era filho de um antigo grevista que foi morto num meeting na célebre greve das docas de 191..., que não tinha ninguém no mundo (AMADO, 2009, p. 193).

$\mathrm{Na}$ fuga de Pedro Bala do reformatório, a narrativa expressa a reprovação do menor em relação a um interno acostumado a entregar os companheiros. Henrique, o delator, já havia denunciado dois outros companheiros ao bedel responsável por manter a ordem durante a noite. $\mathrm{Na}$ madrugada em que o chefe dos capitães da areia empreendia a fuga, o mexeriqueiro despertou e, quando ia soltando o alarme, Pedro Bala o repreendeu:
- Olha, xereta, trata de dormir. Se tu piar, eu te abro a garganta, palavra de Pedro Bala. E se tu disser alguma coisa depois que eu sair... Tu já viu falar nos Capitães da Areia?
- Já.
- Pois eles me vinga (AMADO, 2009, p. 209).

$\mathrm{Na}$ evasão do menor, observa-se um conjunto de táticas e astúcias. A cena começa evidenciando o cenário vigiado do canavial. Os bedéis circulavam pelo canavial quando Pedro Bala vê Sem-Pernas sendo tangido por um dos vigilantes. Ele espera um descuido e passa para o menor um bilhete em que pedia que conseguisse uma corda. No dia seguinte, o chefe dos capitães encontra um punhal e "o rolo de corda fina e resistente" (AMADO, 2009 , p. 208) escondido entre as moitas. Em seguida, "Pedro mete o rolo de corda debaixo do paletó, abre para o dormitório. Um bedel vem descendo a escada com um revólver na mão. Pedro se esconde atrás de uma porta" (AMADO, 2009, p. 208). Ao chegar ao interior do dormitório, esconde os objetos sob o colchão e volta para o canavial. Duas noites depois, o menino lançava a corda que completou com o lençol, dando um nó resistente, que aprendera a fazer com Querido-de-Deus. Após lançar a corda, Pedro acelera a debandada.

Se deixa escorregar pela corda, salta ao chão. O pulo é grande, mas ele já salta correndo. Pula a cerca, após evitar os cachorros policiais que estão soltos. Desaba pela estrada. Tem alguns minutos de vantagem. O tempo dos bedéis se vestirem e saírem em sua perseguição e soltarem os cachorros também. Pedro Bala prende o punhal nos dentes, tira a roupa. Assim os cachorros não o conhecerão pelo faro. E nu, na madrugada fria, inicia a carreira para o sol, para a liberdade (AMADO, 2009, p. 209-210).

Com essa disparada de Pedro Bala para a liberdade, a narrativa expõe o modo de uso das táticas. A espera da ocasião, a rapidez para se valer do momento oportuno e a percepção aguçada são os ingredientes necessários à escapada. $\mathrm{O}$ que se viu na ação do personagem foi a 
elaboração de táticas constituídas a partir do uso de meios e instrumentos marginais, isto é, o rolo de corda, o punhal, o bilhete trocado e o aprendizado do nó. Todos esses artifícios laterais ao cotidiano regrado da casa de custódia.

As pequenas táticas urdidas pelos capitães da areia nas brechas deixadas pelo Estado repressor são como minúsculas máquinas de guerra que se multiplicam no decorrer do romance. Essas fagulhas microfísicas, esses diminutos focos de incêndio são como ínfimos estágios de erosão capazes de causar, em seu conjunto, colapsos nas engrenagens do poder estabelecido. Era por intermédio dessas pequenas astúcias cotidianas que os capitães da areia partiam para enfrentar os condicionamentos impostos pelas armadilhas da opressão social.

Eis a maneira como lutam os "fracos" contra as estratégias do Estado. A história de uma guerrilha empreendida por crianças desprovidas de amparo social é o que se pode ler em Capitães da areia. Um escrito de combate contra um contexto social e jurídico insensível à pobreza e à infância abandonada. Uma narrativa escrita com aqueles que, através de práticas cotidianas transgressoras, enfrentam as autoridades constituídas e trapaceiam as rígidas relações de poder de um arranjo social injusto e desigual.

\section{Referências}

AMADO, Jorge. Bahia de Todos os Santos: guia de ruas e mistérios de Salvador. São Paulo: Companhia das Letras, 2012 .

AMADO, Jorge. Capitães da areia. São Paulo: Companhia das Letras, 2009

CERTEAU, Michel de. A invenção do cotidiano: artes de fazer. 3. ed. Tradução de Ephraim F. Alves e Lúcia Endlich Orth. Petrópolis, RJ: Vozes, 1998.

FOUCAULT, Michel. Sobre a justiça popular. In: Microfísica do poder. 13. ed. Tradução de Roberto Machado. Rio de Janeiro, Graal, 1998.

GINZBURG, Carlo. O queijo e os vermes: o cotidiano e as idéias de um moleiro perseguido pela Inquisição. Tradução de Maria Betânia Amoroso. São Paulo: Companhia das Letras, 2006.

LUDMER, Josefina. O corpo do delito: um manual.Tradução de Maria Antonieta Pereira. Belo Horizonte: Editora da UFMG, 2002 .

Recebido: 18 de março de 2016 Aprovado: 25 de maio de 2016 Contato: marciasrios@terra.com.br 